\title{
O PAI E A PSICANÁLISE: UM ESTUdO SOBRE A FUNÇÃO PATERNA E SUAS CONFIGURAÇÕES NO MUNDO CONTEMPORÂNEO
}

\author{
Thassia Souza Emídio \\ Universidade Estadual Paulista "Júlio de Mesquita Filho" - UNESP. Departamento de Psicologia Clínica, Assis - SP.
}

\begin{abstract}
RESUMO
Este trabalho objetivou refletir sobre a função paterna e suas configurações no mundo contemporâneo. Caracteriza-se como um trabalho teórico-reflexivo em que partimos da Psicanálise, enquanto fonte teórica. Desenvolvemos uma discussão sobre o pai e a psicanálise, passando pelo pai na Horda Primeva, pela função do pai e pela relação desta com os laços sociais. Em seguida, discutimos sobre a função paterna e os modos de subjetivação na contemporaneidade. Diante das reflexões deste trabalho, consideramos sobre a importância da função paterna, na estruturação psíquica e no estabelecimento dos laços sociais, e notamos que as discussões sobre o enfraquecimento da função paterna, na contemporaneidade, nos permite refletir sobre as novas formas de subjetivação, mostrando-nos as manobras do sujeito para lidar com a falta e com sua condição de desamparo. Esperamos que nossas considerações neste estudo, possam contribuir para as discussões sobre a sociedade atual e para as reflexões no campo da Psicanálise.
\end{abstract}

Palavras-chave: Pai; Psicanálise; Contemporâneo.

The father and Psychoanalysis: a study about the paternal function and its configurations on contemporary world.

\begin{abstract}
This work aims to reflect on the paternal function and its settings in the contemporary world. It is characterized as a theoretical-reflective work of psychoanalysis we left, while theoretical source. We develop a discussion about the father and psychoanalysis, through the father in Primal Horde, the role of the father and the relationship between this and social ties. Then we discuss about the paternal function and modes of subjectivity in contemporary. Given the reflections of this work, we consider the importance of the paternal function, the psychic structure and the establishment of social ties, and noted that discussions about the weakening of the paternal role, in contemporary times, allows us to think about new forms of subjectivity, showing us the tricks of the subject to deal with the lack and his helpless condition. We hope that our considerations in this study, may contribute to the discussions on the current society and the reflections in the field of psychoanalysis.
\end{abstract}

Keywords: Father: Psychoanalysis, Contemporary. 


\section{INTRODUÇÃO}

Foi nos tempos da Primeira Guerra Mundial que Freud nos alertou para um estado de malestar na civilização e, passados mais de 80 anos de seus escritos, a psicanálise retoma essa discussão. A sociedade contemporânea e suas configurações têm trazido à tona reflexões sobre a autoridade, a família e os significados dos papéis conjugais e parentais, que apontam para uma nova estruturação de sociedade marcada por novas formas de subjetivação. Nessas discussões, várias vezes somos remetidos a tal estado de mal-estar e abre-se um amplo campo para a discussão. Neste cenário, salta-nos aos olhos uma figura para qual muitas vezes convergem essas discussões: o pai. Colocado por Freud, desde seus primeiros escritos, em um papel fundamental na estruturação psíquica do sujeito e retomado nos textos freudianos sobre a cultura e a organização social, o pai permeia várias obras do autor e ocupa uma função significativa nas discussões psicanalíticas e na explicitação de suas teorias e conceitos. Alguns dizem sobre a morte do pai, outros de sua falência, outros colocam a solução para o estado de mal-estar, na restituição de seu poder enfraquecido; alguns atentam para outras possibilidades de gestão do social, porém, o que se apresenta é um campo de discussões sobre a figura do pai e sua significação.

Diante dessas questões e das reflexões sobre este estado de mal-estar, na atualidade, este trabalho tem como objetivo o estudo da função paterna e suas configurações, no mundo atual, tendo como foco refletir sobre a função paterna no processo de desenvolvimento e estruturação psíquica do indivíduo e suas configurações, na contemporaneidade. As questões que nortearam nossas reflexões foram: qual é a função do pai em Psicanálise? Como se configura a função paterna na contemporaneidade?

Nesse caminho, ao nos debruçarmos sobre essas discussões, encontramos alguns autores, como Birman (2000, 2005, 2006), Kehl (2000, 2003, 2009), Enriquez (1997, 1999, 2006, 2009), Roudinesco (2003) Freire-Costa $(2000,2005)$ e Dor( 1995;2000), que, em seus escritos retomam Freud para explicitar suas ideias. Nesse sentido, para a realização desta pesquisa de caráter teórico-reflexivo, optamos por trabalhar com o referencial psicanalítico. Partimos da Psicanálise, enquanto fonte teórica, para a construção do conhecimento em nossa pesquisa e foi com base na teoria psicanalítica, de suas proposições sobre o processo de estruturação psíquica do indivíduo, das ressonâncias destes na estruturação dos laços sociais e das discussões desenvolvidas por psicanalistas, na contemporaneidade, sobre a função paterna e suas configurações, que construímos o referencial teórico deste trabalho. 


\section{METODOLOGIA}

Para a realização deste estudo, optamos por trabalhar com o método psicanalítico. A Psicanálise foi tomada enquanto método de investigação que pretende a elucidação dos aspectos mentais inconscientes, mesmo que não estejamos dentro do setting terapêutico, ou seja, adotamos a aplicação da psicanálise a uma esfera maior, a da vida social, da cultura, no espírito do que sublinha Mezan (1998, p. 62): “A cultura tomada em seu sentido mais amplo não é estranha à esfera da psicanálise, porque esta não se reduz a um método terapêutico, mas assenta tal método sobre uma teoria da gênese e do funcionamento do psiquismo em geral".

Rezende (1993) busca estabelecer uma relação entre a exegese, a hermenêutica e a interpretação - que foram inicialmente colocadas no contexto da leitura dos textos sagrados, em especial a Bíblia - e a pesquisa em psicanálise. Ao discutir as questões que envolvem uma pesquisa em psicanálise, o autor ressalta que cabe ao pesquisador o exercício de três importantes funções: a do exegeta, a do hermeneuta e a do intérprete.

Nesse sentido, no caminho para o desenvolvimento deste trabalho, coube a nós, a princípio, o exercício da leitura, da pesquisa em biblioteca, do olhar para o texto e sua construção; posteriormente, pudemos envolver-nos com o sentido deste e acrescentar a ele o que pensamos, a nossa leitura, o que pudemos entender e nos apropriar, de modo que só assim pudemos chegar a uma interpretação, ao exercício da busca de dar sentido ao simbólico, aos fenômenos psicanalíticos, ao inconsciente; somente dessa maneira pudemos procurar, nas reflexões propiciadas pelos mitos, a sua voz e o que eles simbolizam, que sentido eles nos trazem e como podemos refletir sobre o mundo contemporâneo e suas configurações, com base em suas contextualizações.

\section{DISCUSSÃO}

Diante de nossas indagações sobre a função paterna, no processo de estruturação psíquica do sujeito e suas configurações, na contemporaneidade, que nortearam a organização do estudo, pudemos perceber que a função paterna pelo olhar psicanalítico se apresenta composta por diversos pais, por diversos momentos em que essa função é exercida.

Para a teoria psicanalítica, o pai é um operador simbólico a-histórico, uma entidade simbólica estruturante do ordenamento psíquico do sujeito. Ao exercer essa função simbólica, o pai ocupa o lugar do representante da autoridade frente à relação mãe e filho, desempenhando o papel de um agenciamento diplomático da realidade. Nessa perspectiva, podemos considerar que 
o pai é o representante simbólico de um terceiro que faz a mediação do desejo da mãe e do filho, sendo sua função a base da estruturação psíquica do sujeito.

Em nosso percurso, ao refletirmos sobre a função paterna para a Psicanálise, retomamos as ideias de Freud (1913), quando se refere a como se deu essa forma de organização do social, retomando o pai da horda primeva ou primitiva, tirânico homem que exercia o seu poder ciumento, guardando todas as mulheres para si e expulsando seus filhos, quando cresciam. Nesse relato do autor, observamos o pai ocupando o cenário psicanalítico como uma ordem simbólica, resultante do assassinato, pelos irmãos, do pai tirânico e do sentimento de culpabilidade vivenciado por eles, após tal ato. Na tentativa de anularem o ato de terem matado o pai, instituem-se a proibição da morte do totem e das relações incestuosas entre os membros do mesmo clã, como também se dá a instauração dessa figura simbólica ordenadora das relações. Assim, podemos considerar que é nas raízes do totemismo que encontramos o surgimento do pai enquanto função simbólica.

Além desses fatores, a leitura freudiana sobre o pai da horda primeva nos trouxe a possibilidade de pensar as questões que envolvem a ambivalência, no complexo paterno. 0 pai tirânico da horda primeva, que possuía todas as mulheres, pode ser pensado como aquele em que não há limitação das exigências sexuais, aquele que tem o falo, que levaria os outros a manter uma relação ambivalente para com ele: a inveja por não ter o que aquele supostamente possui e, por isso, o desejo de matá-lo para assumir o seu lugar. Nesse mesmo movimento, ao ingerirem a carne desse pai, podemos considerar que estes vivenciam uma identificação com o tirano, como uma forma de incorporação de seus atributos e de reforçarem sua identificação com ele. Essa relação ambivalente com o pai é vivenciada pelo sujeito desde o início e tem ressonâncias até a vida adulta, porém, é somente pela condenação desse pai à morte, que este pode ser edificado como Pai Simbólico, como aquele que todos devemos adorar e obedecer. É por causa da culpa pela morte desse pai que temos a submissão dos homens à lei do pai, de uma ordem simbólica que impõe a castração a todos.

Nesse sentido, para que o Pai Real possa ser edificado em Pai Simbólico, este precisa provar que tem o atributo que todos desejam, precisando ser vivenciada uma relação ambivalente com ele: o pai só pode exercer sua função simbólica quando é odiado e admirado.

Diante dessas reflexões, pudemos notar também que o pai é o agente da mediação do desejo da mãe e o filho, ocupando, na teoria psicanalítica, o espaço do pai interditor, que dá continuidade à proibição do incesto, exercendo o papel do terceiro, nessa relação. Para que a interdição se efetue, é necessário que esse pai seja desejado por essa mãe e permita que ela possa 
destinar o seu desejo para outros objetos que não o filho. Nesse sentido, o pai, enquanto função interditora, possibilita o processamento dos primeiros afastamentos necessários para o desenvolvimento da criança e sua estruturação psíquica. É necessário que o desejo de cada um seja mediado pelo pai simbólico, que propicia a interdição da relação incestuosa entre a mãe e o filho e, assim, a transmissão da lei e da autoridade.

O pai como função simbólica desempenha igualmente sua função na dialética edipiana, na qual, a partir da edificação do pai simbólico, esta vai exercer uma influência no processo de estruturação psíquica da criança. No momento pré-edípico, a criança é o objeto fálico da mãe e é pela via da castração que o pai faz sua entrada na relação, estabelecendo uma relação triangular em que vai se produzir uma identificação fálica com o pai e em que este é edificado em sua função simbólica.

Nesse momento, a criança passa a verificar que o pai assume uma consistência significativa, em face do desejo da mãe, e começa a requestionar sua identificação imaginária com o objeto de desejo da mãe, entrando em um momento de incerteza com respeito ao seu desejo; é essa incerteza que coloca a criança ante a castração proferida pela instância paterna.

Desse modo, conforme a criança vai percebendo a presença desse pai e que este é alguém que tem direito ao desejo da mãe, vai-se construindo uma rivalidade fálica na qual a figura paterna passa a ocupar o lugar de um rival, passando a construir uma imagem do pai como aquele que priva, interdita e frustra de sua satisfação inicial, de sua relação de indiferenciação com a figura materna.

Nesse sentido, é o pai o representante do outro, na relação fusional estabelecida entre a mãe e a criança, de sorte que é quando esse pai exerce sua função interditora que a criança é submetida à lei do pai, o que a coloca em contato com a lei do desejo do outro e que esta pode, por conseguinte, vivenciar a alteridade.

A criança, ao perceber a falta e afastar-se de sua mãe, substitui o desejo de ser o falo da mãe, mantendo a relação de indiferenciação entre eles, pelo desejo de ter o falo, vivenciando uma renúncia do objeto inicial, recalcando seu desejo primitivo e construindo um novo significante para o seu desejo.

Podemos imaginar que é nesse processo de afastamento da figura materna, processado pelo estabelecimento da relação triangular e pela submissão do sujeito à lei do pai, que se estabelece uma importante separação na relação mãe e filho, quando a criança faz a transição de ser o falo da mãe, objeto de desejo e satisfação, para ter o falo, instituindo-se para esta a falta, a incompletude, o desamparo. 
É com a vivência que o sujeito passa a ter acesso à ordem simbólica, à linguagem, às leis e à nomeação de seu desejo, colocando o pai em uma outra posição para a teoria psicanalítica, a do que permite o acesso ao simbólico. A partir da interdição efetuada pela instância paterna, o sujeito vivencia uma renúncia simbólica que Ihe permite se apropriar de seu desejo e, como sujeito desejante, poder continuar a significar o objeto primordial do seu desejo. É nesse momento que o sujeito pode reconhecer o outro, vivenciando a alteridade, e pode emergir como sujeito desejante.

Em decorrência, a função paterna exerce sua função estruturante a partir da vivência edípica e da interdição da relação mãe e filho, processo em que, pelos amores edípicos e suas vicissitudes, o sujeito negocia sua relação com o falo, com o desejo e a falta. No processo de transição do ser para o ter o falo, o sujeito, ao vivenciar a castração e a renúncia dessa mãe, objeto de satisfação, passa a organizar algumas construções defensivas neutralizadoras da angústia. Tais defesas vão testemunhar as diferentes formas de o sujeito orientar-se, diante da castração proferida pela instância paterna, de maneira que são elas que orientam o processo de estruturação psíquica do sujeito.

Diante da angústia de castração, o sujeito tem três possibilidades de lidar com ela, de acordo com a teoria psicanalítica proposta por Freud e também discutida por Lacan: a estruturação perversa, a estruturação neurótica (histeria, neurose obsessiva, neurose fóbica) e a estruturação psicótica. Pelas reflexões feitas por ocasião da pesquisa, é possível entender que o pai exerce sua função no processo de estruturação psíquica do sujeito e compreender o seu papel, nessas três estruturas, o que nos permite atentar para sua função simbólica.

\section{RESULTADOS}

Nesse caminho, pudemos retomar as diversas posições que o pai ocupa: o lugar de uma instância simbólica responsável pela transmissão da cultura, da lei, da autoridade, e que tem como função mediar o desejo da criança e o da mãe, no qual ocupa o lugar de interditor, privador e frustrador, na vivência edípica, compondo uma das primeiras identificações do sujeito, com base na função fálica e da atribuição de que só ele o supostamente possui, tendo como herdeiros o superego e o ego ideal, o da instância psíquica que, ao ser edificada, permite o acesso do sujeito ao simbólico e à vivência da alteridade, de sorte que este possa emergir como sujeito desejante e possa assim construir as diferentes defesas para sua negociação diante da falta, do desamparo. Nesse sentido, passamos por um caminho em que diferentes funções são exercidas pelo pai, e que nos colocam diante também da ligação dessa função ao individual e ao social. 
O pai, além de desempenhar a função da estruturação psíquica do sujeito, no seu processo de desenvolvimento, apresenta-se como a base para a civilização, para a organização do social e dos laços entre os irmãos. Ele é a base de sustentação do pacto social, uma vez que a civilização nasceu pela repressão coletiva de nosso desejo de assassinar e ocupar o lugar do pai. O pai é a ordem simbólica que nos impõe a necessidade de uma renúncia pulsional, a fim de vivermos em sociedade, pondo-nos a interdição do incesto e o estabelecimento de regras de reciprocidade.

Na compreensão dessa dinâmica da função paterna entre o individual e o social, a cultura pode ser pensada como uma construção fundamentada na energia libidinal desviada, que, em alguns momentos, protesta contra a civilização, mas que precisa permanecer desviada em sua renúncia praticamente integral, para que a civilização se mantenha. Dessa forma, o pai, por sua exigência de renúncia para a ordenação das relações sociais, é igualmente a base da consciência da culpabilidade e dos laços sociais que podem ser considerados os frutos da inibição das tendências sexuais ligadas à vivência edípica. Neste trabalho, o pai se apresentou em diferentes posições, mas todas elas convergem para a posição central ocupada pela função paterna, na compreensão do processo de estruturação psíquica individual e da organização dos laços sociais.

Dessa forma, em nossas reflexões sobre a função paterna e suas configurações, na contemporaneidade, observamos que a atualidade traz ao nosso olhar novas formas de ser e existir, novas figuras emergem no cenário contemporâneo, como retrato das condições de subjetivação que permeiam o período a que nos referimos.

Com o advento da modernidade e o desenvolvimento da racionalidade científica, vivemos um enfraquecimento do poder do pai, que trouxe ressonâncias para as formas de subjetivação, na contemporaneidade.

Nesse cenário, o pai aparece como uma figura enfraquecida, mas que ainda ocupa o seu lugar, quando pensamos sobre o sujeito e sua constituição subjetiva, como quando refletimos sobre o sujeito e sua relação com o social. O enfraquecimento do poder do pai nos coloca ante um momento de mal-estar, em que muitas vezes a perda de certos referenciais leva o sujeito a construir uma condição narcísica de existência, onde o outro é negado e a alteridade não pode ser vivenciada. Nessas novas maneiras de subjetivação, emergem as compulsões, a drogadição, os delírios em busca de uma perfectibilidade corporal, o consumo exacerbado e a banalização do mal e da violência, como manobras do sujeito para lidar com a falta, com nossa condição desamparada. 
Porém, nesse cenário, emergem também outros modos de vivenciar essa falta, de dar conta de nosso desamparo inicial e, nessa condição, surgem, como forma de gestão do social, o sentimento fraternal, estratégias são construídas pelos irmãos diante deste estado de mal-estar. Famílias se reorganizam, pequenos grupos entram nesse cenário, ocupando força política e social, apontando-nos sobre como lidar com esse mal-estar, uma possibilidade de reescrevermos o pacto civilizatório a partir dos laços de reciprocidade e de uma retomada da confiança do sujeito no outro e nas formações coletivas.

\section{CONCLUSÃO}

A partir de nossas reflexões, notamos a importância da função paterna, na estruturação psíquica do indivíduo e no estabelecimento dos laços sociais, além das ressonâncias dessa função, no decorrer de toda sua vida. Verificamos também que a função paterna, na contemporaneidade, traz à tona novas formas de subjetivação, novas figuras emergem no cenário contemporâneo, mostrando-nos as manobras do sujeito para lidar com a falta, com o desamparo, colocando-nos diante de um estado de mal-estar para o qual devemos atentar e partir em busca de dar conta dele.

Em todo o caminho deste trabalho, em que objetivamos refletir sobre a função paterna e suas configurações, no mundo contemporâneo, novas questões emergiam, sinalizando que esta pesquisa não se finaliza com estas considerações, pois elas trazem também novas indagações.

O refinamento dos crimes, a violência, a negação do outro nos trazem também a necessidade de reflexões sobre as relações de alteridade, a relação com o outro e a questão da banalização do mal, como um retrato das relações contemporâneas. As presentes questões indicam as novas possibilidades de gestão do social e a necessidade de uma retomada dos laços recíprocos e da confiança do sujeito no outro. Nesse caminho, pensar as configurações dos laços fraternos e toda a amplitude dessa temática se apresenta também como um questionamento, fruto das reflexões que desenvolvemos até aqui.

Finalizamos, portanto, nosso trabalho nesta pesquisa, salientando que, a partir dele, acontecem novos desdobramentos, novas questões e que ele não se encerra aqui, significando um passo no caminho de nossos questionamentos sobre a busca do entendimento do sujeito e de suas relações. 


\section{REFERÊNCIAS}

BIRMAN, J.(2005). Mal - estar na atualidade A psicanálise e as novas formas de subjetivação. Rio de Janeiro: Civilização Brasileira.

BIRMAN, J.(2006)Arquivos do mal-estar e da resistência. Rio de Janeiro: Civilização Brasileira.

DOR, J.(1991) O Pai e sua função em Psicanálise. Rio de Janeiro: Jorge Zahar.

DOR,J.(1997) Estruturas e clínica psicanalítica. Rio de Janeiro: Taurus. ENRIQUEZ,E. (1997) Perda do Trabalho, perda da identidade. In CARVALHO NETO, A.; NABUCO, M. R. Relações de Trabalho Contemporâneas. Belo Horizonte: IRT -PUC Minas.

FRAZER, J.G. (1946[1910])Totemismo e Exogamia. Buenos Aires: Kier.

FREUD, S.(1996) Edição Standard Brasileira das Obras Psicológicas completas de Sigmund Freud. Tradução de Jayme Salomão. Rio de Janeiro: Imago, v. I a v. XXIII.

KEHL, M. R.(2003) Sobre Ética e Psicanálise. São Paulo: Companhia das Letras, 2003.

LACAN, J. (1990[1958]) O seminário livro 5 - As formações do Inconsciente. Rio de Janeiro: Zahar. . (1998[1949]) O estádio do espelho como formador da função do eu. In: LACAN, J. Escritos. Trad. Vera Ribeiro. Rio de Janeiro: Zahar.

LASCH, C.(1983) Cultura do narcisismo. Rio de Janeiro: Imago.

MEZAN,R. (2006) Freud Pensador da Cultura. São Paulo: Companhia das Letras. 